\title{
Angular Effects of Z-Plasty Technique on Extent of Relaxation of Contracted Scar, Cosmetic Appearance and Tip Necrosis in Dogs
}

\author{
Muhammad Asif ${ }^{1}$, Muhammad Arif Khan', Shehla Gul Bokhari', Ghulam Abbas ${ }^{2, *}$, \\ Muhammad Sajid ${ }^{3}$, Muhammad Ijaz ${ }^{1}$, Aisha Mahmood ${ }^{4}$ \\ ${ }^{1}$ Department of Clinical Medicine and Surgery, Faculty of Veterinary Science, University of Veterinary and Animal Sciences, Lahore, \\ Pakistan \\ ${ }^{2}$ Department of Animal Production, Riphah College of Veterinary Sciences, Riphah International University, Lahore, Pakistan \\ ${ }^{3}$ Department of Anatomy, Riphah College of Veterinary Sciences, Riphah International University, Lahore, Pakistan \\ ${ }^{4}$ Institute of Pharmacy, Physiology and Pharmacology, University of Agriculture, Faisalabad, Pakistan
}

Copyright $\bigcirc 2017$ by authors, all rights reserved. Authors agree that this article remains permanently open access under the terms of the Creative Commons Attribution License 4.0 International License

\begin{abstract}
Z-plasty is a plastic surgery technique which is used to improve the functional and cosmetic appearance of a scar by redirecting it into better alignment and allowing the closure of a large wound by increasing circumference of its orifices. This experimental study was executed to evaluate the extent of relaxation of contracted scar, cosmetic appearance and tip necrosis in dogs by using Z-plasty technique at different angles, i.e. $45^{\circ}, 60^{\circ}$ and $75^{\circ}$, respectively. 18 mongrel dogs were randomly selected and divided in three groups (A, B and C) comprising six dogs each; after induction of scar tissue, Z-plasty was applied at $45^{\circ}$ in Group A, $60^{\circ}$ in Group B and $75^{\circ}$ in Group C, respectively. \% Gain in length was superior for the $60^{\circ}$ group $(\mathrm{P}<0.05)$, as compared with the $45^{\circ}$ and $75^{\circ} \mathrm{Z}$-plasty, respectively. Tip Necrosis Status and cosmetic appearance for the $60^{\circ}$ group were also found superior $(\mathrm{P}<0.05)$ than at $45^{\circ}$ and $75^{\circ}$, respectively. The results of the experimental trial showed that the parameters of extent of relaxation of the contracted scar, cosmetic appearance and tip necrosis, were mainly governed by two factors, (1) length of contracted scar and (2) angle of Z-plasty technique. Conclusively, $60^{\circ}$ Z-plasty serves a better option for correction of burn scar contractures since it provides average gain in length, good cosmetic appearance and causes no tip necrosis.
\end{abstract}

Keywords Burn Scar Contracture, Scar Revision, Z-Plasty, Tip Necrosis, Dogs

\section{Introduction}

Z-plasty is a plastic surgery technique which incorporates a Z- shaped skin incision, composed of one central and two lateral limbs, with two triangular flaps of equal sizes and these flaps are raised on opposite sides of the two ends of the "Z", and then transposed to each other [3, 14].Z-plasty is mostly indicated for burn scar contractures which are one of the most pressing challenges to burn-patients $[16,19,20]$ because they result in poor aesthetic appearance, functional impairment and musculoskeletal discomfort.

Initially, some non-surgical procedures like appropriate wound care, splinting and physiotherapy have been used to release the scar. Medical management serves transient relief, however, despite proper application of these treatments, contractures still occur $[12,21]$. Hence, permanent relief from burn scar necessitates implication of some relaxing incision. For this purpose, many surgical procedures like skin grafting, flap technique, Z-plasty, Y-V advancement, W-plasty and combinations of the above-mentioned techniques have been used as relaxing incision $[8,18]$.

Regarding various techniques employed for correction of scars, although the primary aim of each is to lengthen the scar, yet Z-plasty and its modifications supervene over other techniques, since they provide superior lengthening-to-narrowing ratio (Vegetar and Hage, 1997). Z-plasty is a good choice for linear and narrow contracted scar $[6,22]$. The major advantage is that Z-plasty can be performed in an area of high skin tension to allow skin relaxation and lengthening [14]; Z-plasty not only improves the functional and cosmetic appearance of scars, rather, it also prevents the contracture of linear scars [11]. Moreover, it also redirects a scar into better alignment with the line of least skin tension or a natural skin fold to allow the closure of large wounds by increasing the circumference of its orifices [1].

Although, a great wealth of literature is available on various issues of reconstructive surgery and the treatment of 
post burn contractures [5]. However, condition of the problem, burn severity and choice of technique is still debatable $[17,13]$. Considering these points in view, the present study was planned toevaluate the extent of relaxation of contracted scar,cosmetic appearance and tip necrosis at $45^{\circ}, 60^{\circ}$ and $75^{\circ}$ by using Z-plasty technique.

\section{Materials and Methods}

After approval by the Animal Ethical Committee,this experimental study of 3 months' duration was executed at Surgery Section, (Dept. of Clinical Medicine \& Surgery), University of Veterinary and Animal Sciences, LahorePakistan.For this purpose, a total number of 18 adult healthy mongrel dogs were selected and randomly divided into three groups viz., Groups A, B and C, comprising six dogs each. A deep partial thickness burn wound was induced on the right thigh region of each dog using electrocautery into the reticular layer of dermis. The wound healed within 3 to 7 weeks with severe scarring, contraction and poor aesthetic appearance. After inducingscar, Group A dogs were allocated for Z-plasty at $45^{\circ}$ and Group B and C dogs were allocated for Z-plasty at $60^{\circ}$ and $75^{\circ}$, respectively.

\section{Surgical Technique}

\section{Site Preparation and Anesthesia Induction}

The surgical site was prepared aseptically by clipping, washing, and scrubbing of the surgical site; sterile surgical drapes were then placed around the surgical area and secured to patient skin using towel clamps [14]. The dogs were premedicated using an intramuscular injection of atropine sulphate@ @ $0.03 \mathrm{mg} / \mathrm{kg}$ (Atrostar $\AA$, Star Laboratories, Pakistan). Anesthesia was then induced using a combination of ketamine and xylazine $\mathrm{HCl} @ 0.5 \mathrm{mg} / \mathrm{kg}$ (Xylaz ${ }^{\circledR}$, Farvet, Holland), intravenously.

\section{Skin Incision}

A vertical incision was made through the skin along the lines of contraction using a number-15 scalpel blade. The skin flaps resulting from incision were undermined at the level of subcutaneous tissue to produce two triangular flaps of equal size and shapes. Thesetriangular flaps were then transposed with each other. During transposition, the upper flap was placed at the position of the lower flap and vice versa. This transposition of triangular flaps not onlycaused redirection of the central limb at appropriate angle and a disruption of straight scar into a non-linear $\mathrm{Z}$ configuration, but also resulted in gain in the length of the original scar limb.

\section{Skin Closure}

After transposition, the skin was closed by using non absorbable suture material (Mersilk 3/0) with simple interrupted suture pattern (Bouladaas et al., 2004). Topical antibiotics were used to minimize the risk and complications as the Z-plasty technique may be complicated by wound infection, hematoma formation and tip necrosis [11].

In group $\mathrm{A}$ dogs, $\mathrm{Z}$ incision was made by taking scar area as middle part of $Z$ and arms of $Z$ were connected at angle of $45^{\circ}$. Similarly in groups $B$ and $C$, the $Z$ incision was made and arms of $\mathrm{Z}$ were connected at angle of $60^{\circ}$ and $75^{\circ}$ respectively. The triangular area was undermined to make a triangular flap. Both triangular flaps were transposed to each other and skin was sutured with non-absorbable suture material (Mersilk 3/0) with simple interrupted suture pattern.

\section{Post-Operative Care}

Post-operatively, the dogs were monitored for behavior changes, vitals (TPR), feeding, defecation, urination and wound healing/ complications.

\section{Parameters of Evaluation}

The operative technique was evaluated on the basis of

1. Physical findings

2. Wound healing

3. Extent of relaxation of contracted scar at $45^{\circ}, 60^{\circ}$ and $75^{\circ}$

4. Cosmetic appearance at $45^{\circ}, 60^{\circ}$ and $75^{\circ}$

5. Tip Necrosis at $45^{\circ}, 60^{\circ}$ and $75^{\circ}$

\section{Data Analysis}

Data regarding \% gain in length was calculated by using the formula:

\section{Percentage Gain $=$ Original scar length / obtained length $\times 100$.}

The data thus obtained was analyzed according to Completely Randomized Design (CRD) under factorial arrangements using Analysis of Variance (ANOVA) technique [15].

\section{Results}

\section{1) Physical findings}

The vitals, viz. TPR (Temperature, Pulse and Respiration) were recorded twice daily in all experimental dogs.On an average, the TPR values in Group A dogs were within normal range, i.e. $39.5^{\circ} \mathrm{C}$ (temperature), 103 beats $/ \mathrm{min}$ (pulse), and $25 / \mathrm{min}$ (respiration), except dogs \#3 and \# 6 which suffered slight hypothermia $\left(37^{\circ} \mathrm{C}\right)$ during the first 24 hours post-surgery.Average TPR values recorded in dogs of 
Group $\mathrm{B}$ and $\mathrm{C}$ were also within normal range, i.e. $40^{\circ} \mathrm{C}, 102$ beats/minute, and 24 /minute (respiration). However, dog \# 4 in Group B and dog \# 2 inGroup C suffered transient hypothermia. Yet, with proper treatment, both dogs recovered well and the temperature in these dogs rebounded towards the normal range as for all other dogs.

\section{2) Wound healing}

The wound healed satisfactorily in all dogs however, wound healing took slightly longer than the anticipated normal time. The wound healing was delayed inGroup A dogs due to tip necrosis and wound healed in 4-7 weeks. While in Groups B and C, where Z-plasty was applied at $60^{\circ}$ and $75^{\circ}$, respectively [7], the wound healed in 3-4 weeks and 3-7 weeks, respectively.

\section{3) Extent of relaxation of contracted scar at $45^{\circ}, 60^{\circ}$ and $75^{\circ}$}

The $\%$ Gain in length at $45^{\circ}$ Z-plasty was found to be highest (47.50\%) in Dog \# 1 and lowest (35.00\%) in Dog \# 6 . $\mathrm{P}=0.001^{* *}\left(\right.$ Table 1). Similarly, $\%$ Gain in length at $60^{\circ}$ Z-plasty was found to be highest $(72.50 \%)$ in Dog \# 1 and lowest $(45.00 \%)$ in Dog \# $6 \mathrm{P}=0.002 *$ (Table 1) while \% Gain in length at $75^{\circ} \mathrm{Z}$-plastywas found to be highest $(120 \%)$ in Dog \# 1 andlowest (95.00\%) in Dog \# $6 \mathrm{P}=0.001 * *$ (Table 1).Among the Groups, highest \% Gain in length(120\%) was found in $\operatorname{dog} \# 1$ of group $\mathrm{C}$ and lowest (35\%) in dog \#6 of group A $\mathrm{P}=0.000004$ (Table 1)

Table 1. Measurements of percent gain in length of contracted scar at $45^{\circ}$, $60^{\circ}$ and $75^{\circ}$ in experimental dogs

\begin{tabular}{|c|c|c|c|c|}
\hline Dog No. & Group A & Group B & Group C & P-Value \\
\hline 1 & 47.50 & 72.50 & 120.00 & \\
\cline { 1 - 4 } 2 & 44.73 & 71.00 & 118.42 & \\
\cline { 1 - 4 } 3 & 42.85 & 65.70 & 111.42 & \multirow{2}{*}{0.000004} \\
\cline { 1 - 4 } 4 & 43.33 & 63.33 & 110.00 & \\
\cline { 1 - 4 } 5 & 36.00 & 56.00 & 104.00 & \\
\cline { 1 - 4 } 6 & 35.00 & 45.00 & 095.00 & \\
\cline { 1 - 4 } P-Value & $0.001 * *$ & $0.002 *$ & $0.001 * *$ & \\
\hline
\end{tabular}

Group $A: \%$ gain in length at $\mathbf{4 5}^{\circ}$

Group B:\% gain in length at $60^{\circ}$

Group $C: \%$ gain in length at $75^{\circ}$

$P<0.005$ shows significant association

\section{Tip necrosis status at $45^{\circ}, 60^{\circ}$ and $75^{\circ}$}

Group A dogs treated with Z-plasty at $45^{\circ}$ showed tip necrosis while group $\mathrm{B}$ and $\mathrm{C}$ dogs treated with Z-plasty at $60^{\circ}$ and $75^{\circ}$ showed no tip necrosis. Tip necrosis Status at $45^{\circ}, 60^{\circ}$ and $75^{\circ}$ showed statistical significance $\mathrm{P}=0.0001234^{*}$ ( Table 2)

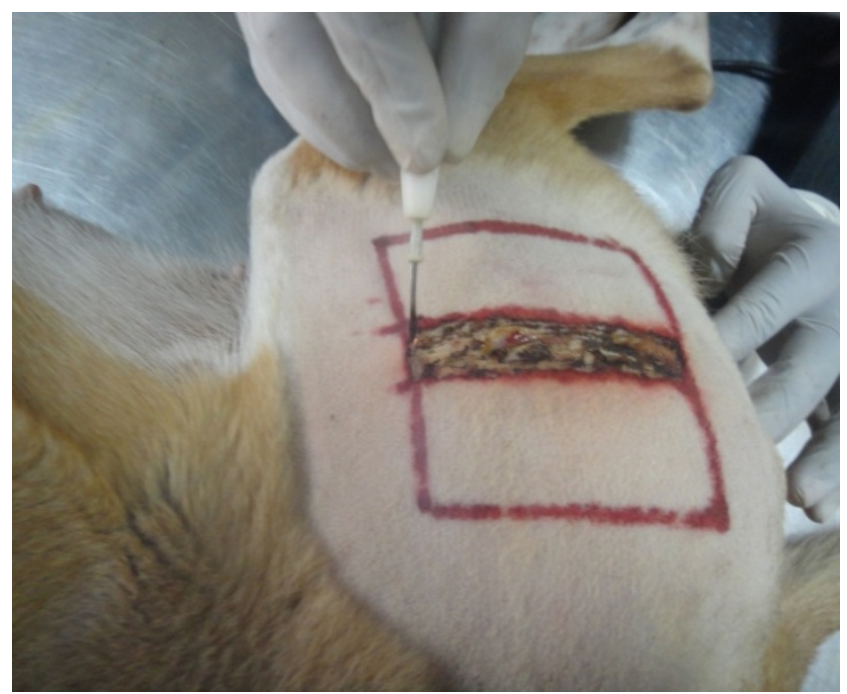

Figure 1. Induction of deep partial-thickness wound through epidermis and into papillary dermis

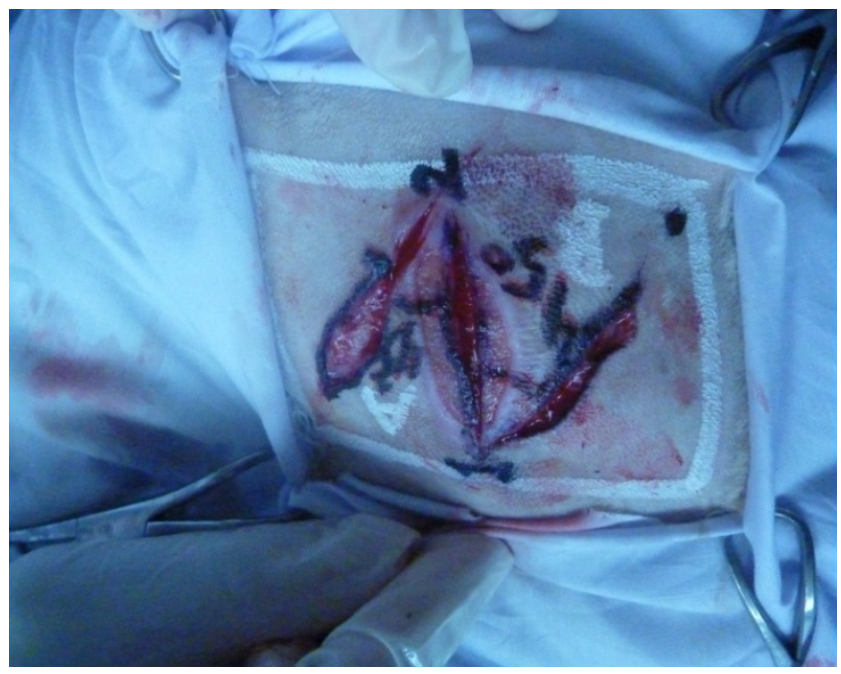

Figure 2. Z-plasty technique applied at $45^{\circ}$ angle.

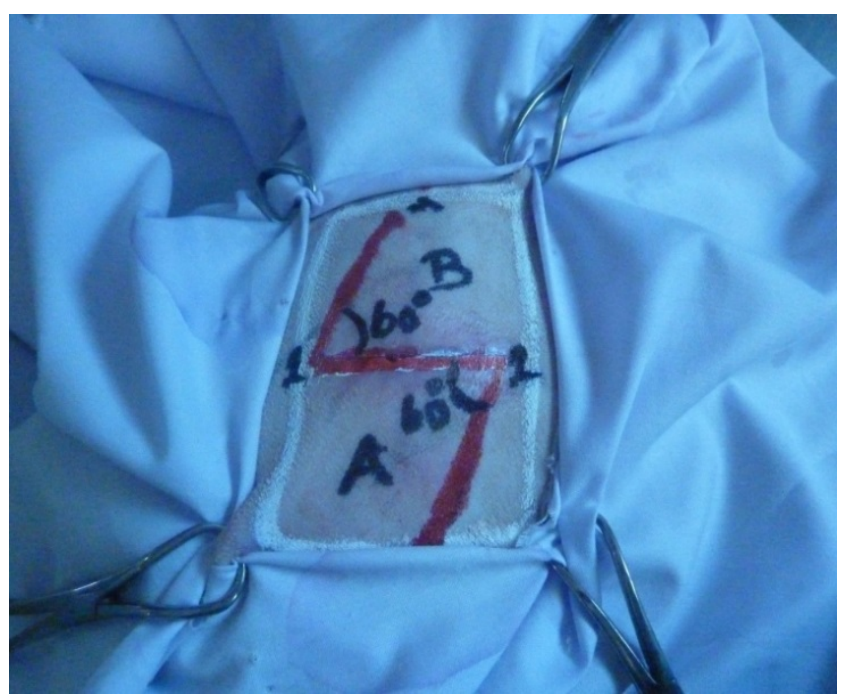

Figure 3. Z-plasty technique applied at $60^{\circ}$ angle. 


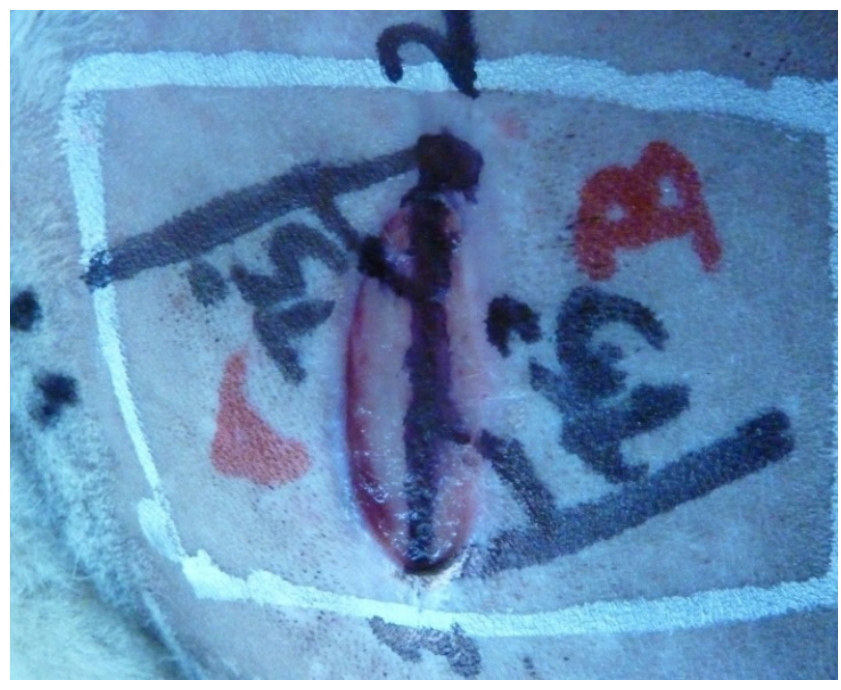

Figure 5. Z-plasty technique applied at $75^{\circ}$ angle.

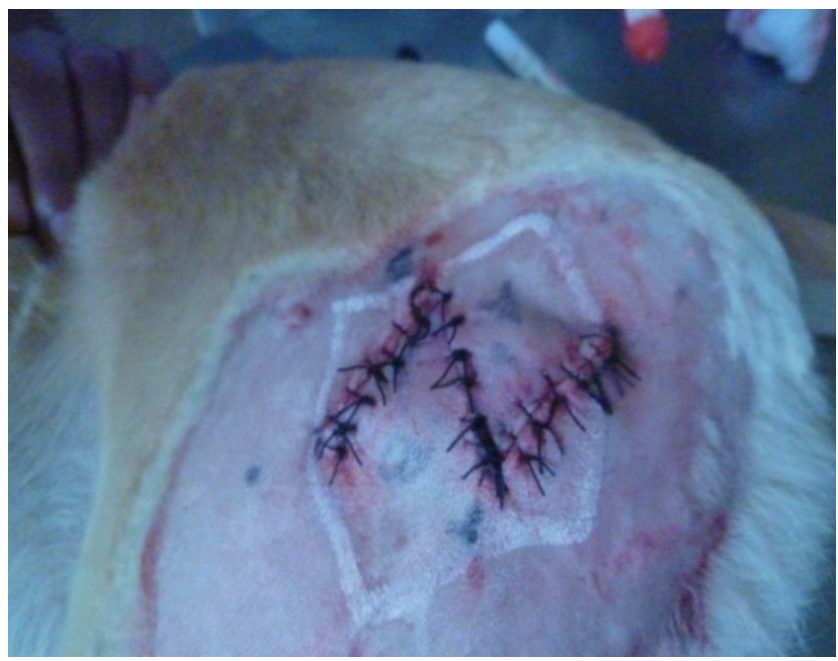

Figure 6. Suturing of Z-plasty incision given at $60^{\circ}$ angle.

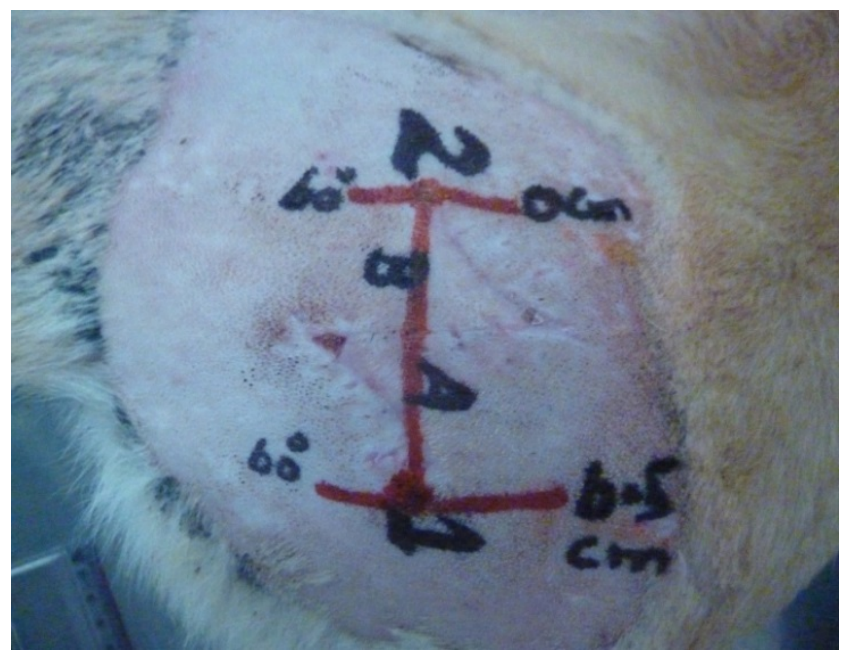

Figure 7. Post-operative measurements of Z-plasty technique done at $60^{\circ}$ angle.

\section{Cosmetic appearance status at $45^{\circ}, 60^{\circ}$ and $75^{\circ}$}

The cosmetic appearance status at $45^{\circ}, 60^{\circ}$ and $75^{\circ}$ showed statistical high significance. $\mathrm{P}=0.000^{* * *}$ ( Table 2).

Table 2. Measurements of Tip necrosis and cosmetic appearance of contracted scar at $45^{\circ}, 60^{\circ}$ and $75^{\circ}$ in experimental dogs

\begin{tabular}{|c|c|c|c|c|c|}
\hline Parameter & Status & \multicolumn{3}{|c|}{ Angles } & \multirow{2}{*}{ P value } \\
\hline & & $\mathbf{4 5}^{\circ}$ & $\mathbf{6 0}^{\circ}$ & $\mathbf{7 5}^{\circ}$ & \multirow{2}{*}{$0.0001234^{* *}$} \\
\hline \multirow{2}{*}{ Tip Necrosis } & Positive & $6^{* *}$ & 0 & 0 & \\
\cline { 2 - 5 } & Negative & 0 & 6 & 6 & \\
\hline \multirow{3}{*}{$\begin{array}{c}\text { Cosmetic } \\
\text { Appearance }\end{array}$} & Bad & 6 & 0 & 0 & \multirow{2}{*}{$0.000^{* *}$} \\
\cline { 2 - 5 } & Good & 0 & $6^{*}$ & 0 & \\
\cline { 2 - 5 } & Fair & 0 & 0 & 0 & \\
\hline
\end{tabular}

$P<0.005$ shows significant association

\section{Discussion}

The Z-plasty technique was evaluated on the basis of physical findings, wound healing, extent of relaxation of contracted scar, cosmetic appearance and tip Necrosis at $45^{\circ}$, $60^{\circ}$ and $75^{\circ}$, respectively. Among vital signs, the temperature, pulse and respiration in all three groups $\mathrm{A}$ and $\mathrm{B}$ and $\mathrm{C}$ were recorded to increase slightly, but became normal after a few days. The wound healed satisfactorily in all dogs. However, wound healing took slightly longer than the anticipated normal time, which could be attributed to temperatures. Delay in wound healing due to temperature fluctuations has also been documented upon by Fossum, [4]; Jain and Shakya, (2009).

In Group A dogs treated with z-plasty at $45^{\circ}$, the percentage gain in length was found to increase from $35 \%$ $47.5 \%(\mathrm{P}<0.05)$. This was in agreement with similar findings reported by Cochran et al. [2] that Z-plasty at $45^{\circ}$ yields $50 \%$ increase in length. The difference may be attributed due to difference in skin elasticity. Pomaranski et al. [9] described that actual gain in length depends on skin elasticity and tissue mechanics. Similarly, the percentage gain in length in Group B dogs treated with Z-plasty at $60^{\circ}$ was found to increase from $45 \%-72.5 \%(\mathrm{P}<0.05)$. This was also in close agreement of the findings of Cochran et al. [2], who reported a $75 \%$ increase in length with $60^{\circ}$ Z-plasty, and Rohrich and Zbar [10], who reported a total increase in length of $41 \%$ to $63 \%$ with $60^{\circ}$ Z-plasty procedure. The slight difference in reported values may however, be attributed to differences in skin elasticity, since Pomaranski et al. [9] described that actual gain in length depends on skin elasticity and tissue mechanics. Similarly, the percentage gain in length in Group C dogs treated with Z-plasty at $75^{\circ}$ was found to increase from $95 \%$ to $120 \%(\mathrm{P}<0.05)$. This was in complete agreement with the findings of Cochrann et al. [2] who documented upon a $120 \%$ increase in length with $75^{\circ}$ Z-plasty. 
On the whole, it was concluded that, the percentage gain in length depends on the length of contracted scar and angle of the Z-plasty. The greater the initial length of contracted scar the higher is the percentage gain in length and vice versa. Similarly, the wider the angle, the higher is the percentage gain in length.

Tip necrosis is a common sequela of plastic reconstructive surgery techniques. In our study, Group A dogs treated with Z-plasty at $45^{\circ}$ showed tip necrosis, while Group B and C dogs treated with Z-plasty, respectively at $60^{\circ}$ and $75^{\circ}$, showed no tip necrosis $(\mathrm{P}<0.05)$. Hence, the cosmetic appearance of dogs that underwent Z-plasty at $45^{\circ}$ weas scored bad whereas for dogs that underwent Z-plasty at $60^{\circ}$ and $75^{\circ}$, were scored good and fair respectively $(\mathrm{P}<0.05)$.

\section{Conclusions}

Conclusively, it was inferred that $\mathrm{Z}$ plasty at $60^{\circ}$ proved better in terms of average gain in length, good cosmetic appearance and no tip necrosis. The $60^{\circ} \mathrm{Z}$-plasty supervenes over the other two techniques, since $\mathrm{Z}$ plasty at $45^{\circ}$ caused tip necrosis, and $\mathrm{Z}$ plasty at $75^{\circ}$ offered greater difficulty for transposition of triangular flaps, thus resulting in some degree of tip necrosis.

\section{REFERENCES}

[1] Aasi, S.Z. (2010). Z-Plasty Made Simple. Dermatology Research and Practice Bouladaas, M., F. Mourtada. M. Lahlou, D. Moudjir, L. Essqualli, F. Alaoui, L. Benchekroun, N. El Jazouli and M. Kzadri (2004). The Interest of Z-plasty in the treatment of cervico-facial burns sequelae. Ann of burns and fire disaster. 17(3): 142-144.

[2] Cochran, C.S., R.J. DeFatta and A.C. Brenski (2006). Congenital midline cervical cleft: a practical approach to Z-plasty closure. Int J Pediatr Otorhinolaryngol. 70(3): 553-559.

[3] Daw, J. L. and P.K. Patel (2003). Double-opposing Z-plasty for correction of midline cervical web. J Craniofac Surg. 14(5): 774-778.

[4] Fossum, T.W. (2002). Surgery of the integumentary system in small animalsurgery. 2nd Ed. Elsevier Science Co, Missouri, USA, pp: 136.

[5] Gulati, S., B.B. Joshi and S.M. Milner (2004). Use of Joshi External Stabilizing System in postburn contractures of the hand and wrist: a 20-year experience. J Burn Care Rehabil. 25(5): 416-420.
[6] Hudson, D.A. (2000). Some thoughts on choosing a Z-plasty: the $\mathrm{Z}$ made simple. Plast Reconstr Surg. 106(3): 665-671.

[7] Jain, M. and M. Shakya (2009). Study of temperature variation in human peripheral region during wound healing process due to plastic surgery. Appl. Math Sci. 3(54): 2651-2662.

[8] Peker, F. and O. Celebiler (2003). Y-V advancement with Z-plasty: an effective combined model for the release of post-burn flexion contractures of the fingers. Burns. 29(5): 479-482.

[9] Pomaranski, M.R., E.A. Krull and M.R Balle (2005). Use of the Z-plasty technique for forehead defects. Dermatol Surg. 31(12): 1720-1723.

[10] Rohrich, R.J. and R.I Zbar (1999). A simplified algorithm for the use of Z-plasty. Plast Reconstr Surg. 103(5): 1513-1517.

[11] Salam, G.A. and J.P. Amin (2003). The basic Z-plasty. Am Fam Physician. 67(11): 2329-2332.

[12] Salisbury, R.E. (2000). Reconstruction of the burned hand. Clin Plast Surg. 27:65-69.

[13] Schneider, J.C., R. Holavanahalli, P. Helm, R. Goldstein and K. Kowalske (2006). Contractures in burn injury: defining the problem. J Burn Care Res. 27(4): 508-514.

[14] Slatter, D.H. (2003). Textbook of small animal surgery. Vol.2. Elsevier Health Sciences.

[15] Steel, R.G.D., J.H. Torrie and D.A. Dickie (1997). Principles and procedures of Statistics-A biometric approach. 3rd Edit. McGraw-Hill Book publishing company, Toronto, Canada.

[16] Sterling, J.P., D.M. Heimbach and N.S. Gibran (2010). 15 Management of the Burn Wound.

[17] Suchanek, I., H. Rihova, Y. Kaloudova and R. Mager(2003). Reconstructive surgeries after extensive burns in children. Acta Chir Plast. 45:139-143.

[18] Tsai, F.C., J.Y. Yang, S. Mardini, S.S. Chuang and F.C Wei (2004). Free split-cutaneous perforator flaps procured using a three-dimensional harvest technique for the reconstruction of postburn contracture defects. Plast Reconstr Surg. 113(1): 185-193.

[19] Ulkur, E., C. Acıkel, R Evinc and B. Celikoz (2006). Use of rhomboid flap and double Z-plasty technique in the treatment of chronic postburn contractures. Burns. 32(6): 765-769.

[20] Vegter, F and J.J. Hage (1997). A theoretical consideration of extensions of the Z-plasty principle. Eur J Plast Surg. 20: 71-76.

[21] Voulliaume, D., A. Mojallal, J.P. Comparin and J.L Foyatier, J.L (2005). Severe hand burns and flaps: indications. Ann Chir Plast Esthet. 50(4): 314-319.

[22] Yilmaz, S., O. Yenidunya, A..R. Ercocen, M. Saydam, E. Seven, H. Sezer and P. McTurk (2003). The seven flap Z-plasty revisited. Burns. 29(8): 849-853. 